\title{
Estudo exploratório da demanda potencial para um sistema de compartilhamento de bicicletas pedelecs
}

\author{
Exploratory study of the potential demand for a pedelec bike-sharing system
}

Leonardo Dal Picolo Cadurin, Antônio Nélson Rodrigues da Silva

\section{Resumo}

O objetivo deste estudo exploratório é apresentar e discutir os resultados de um procedimento para avaliar a demanda potencial por um sistema de bicicletas pedelecs compartilhadas no campus de São Carlos da Universidade de São Paulo (USP). Formado por duas áreas separadas por uma distância de 4,5 km, o campus parece ser particularmente adequado para implantação deste tipo de sistema de transporte. 0 procedimento proposto permite traçar um perfil do público-alvo. Permite ainda verificar a preferência entre os ônibus operados pela própria universidade e as pedelecs compartilhadas, visando os deslocamentos entre áreas. Para tanto, faz uso das técnicas de preferência declarada e redes neurais artificiais, para as etapas de coleta e análise dos dados, respectivamente. A partir das respostas de 397 estudantes foi possível identificar que o esforço físico, condições meteorológicas, tempo de viagem e ausência de ciclovias são fatores que restringem o uso de bicicletas convencionais. Lotação excessiva, horários de partida fixos, ausência de controle sobre o início da viagem e distância de caminhada são aspectos importantes para as pessoas não utilizarem os ônibus operados pela USP. Sobre a preferência por pedelecs, a escolha é influenciada pela presença de ciclovias/ciclofaixas, da lotação do ponto de ônibus da USP e das condições meteorológicas.

Palavras-chave: Sistema de compartilhamento de bicicletas. Preferência declarada. Pedelec. Demanda. Campus universitário.

LDPC é Engenheiro Civil, Mestre em Engenharia de Transportes, e-mail: leonardodpc88@gmail.com ANRS é Arquiteto, Doutor em Engenharia de Transportes, e-mail: anelson@sc.usp.br 


\section{Abstract}

The objective of this exploratory study is to introduce and discuss the results of a procedure developed for assessing the potential demand for a pedelec bike-sharing system at the São Carlos campus of the University of São Paulo (USP). Formed by two areas that are $4.5 \mathrm{~km}$ away from one another, the campus seems to be particularly suited for the implementation of this sort of transportation system. The approach can be used to identify target groups and to check users' preferences when choosing between the buses operated by the university and shared pedelecs to travel between the two areas. Data collection and data analysis are conducted, respectively, with stated preference surveys and artificial neural networks. The responses of 397 students suggest that the physical effort involved in cycling, unfavorable weather conditions, long travel times, and the absence of cyclepaths are the main barriers to the use of conventional bicycles. Overcrowding, inflexible and limited departure times, and long walking distances to reach the bus stops are the main obstacles for the use of the buses operated by the university. The selection of pedelecs is influenced mainly by the existence of cycle paths, the number of passengers at the university bus stop, and the weather conditions.

Keywords: Bike-sharing systems. Stated preference. Pedelec. Demand. University campus.

\section{Introdução}

A mobilidade urbana focada em modos motorizados individuais atualmente é vista como um dos maiores problemas das médias e grandes cidades. Dentre os diversos polos geradores de viagens (PGV), as universidades correspondem a um importante e impactante PGV, sendo responsáveis por significativos volumes de viagens produzidas e atraídas regularmente. Desse modo, as políticas de transportes das universidades influenciam diretamente na mobilidade urbana das cidades em que estão inseridas. Assim como as áreas urbanas, os campi universitários brasileiros possuem, em geral, infraestrutura e política voltada principalmente para os deslocamentos realizados por modos motorizados individuais, seja por meio da utilização de espaço para estacionamento ou pela construção e manutenção do sistema viário.

O campus de São Carlos da Universidade de São Paulo (USP) existe desde 1956 e está localizado próximo à região central da cidade. Em 2002 a universidade adquiriu uma segunda área, denominada Área 2 , que está a cerca de $4,5 \mathrm{~km}$ da Área 1 . Atualmente o campus conta com aproximadamente 5200 alunos(as) de graduação e 2600 alunos(as) de pós-graduação. Alguns cursos de graduação e programas de pós-graduação se concentram ou possuem atividades na Área 2, exigindo deslocamentos dos(as) estudantes com certa frequência, já que a maior parte das moradias estudantis se concentra na região em torno da Área 1, devido à proximidade ao comércio e serviços. Por conta disso, 34\% do total de estudantes do campus frequenta regularmente a Área 2, conforme pesquisa realizada por Oliveira (2015). Dentre os(as) estudantes que se deslocam com regularidade até a Área 2, 81\% são graduandos(as) e 19\% pós-graduandos(as), de acordo com a mesma pesquisa.

Devido a essa necessidade de deslocamentos, a universidade fornece ônibus, em uma grade de horários baseada nas aulas de graduação. Entretanto, há alunos(as) que não são contemplados(as) pelos horários disponíveis, principalmente os(as) que realizam atividades de pesquisa, seja de iniciação científica ou de pós-graduação. Considerando a tendência de ampliação do campus, a expectativa é que a quantidade de deslocamentos até a Área 2 aumente consideravelmente nos próximos anos. Desse modo, a existência de uma demanda regular entre as duas áreas e o fato da distância entre as mesmas ser apropriada para o modo cicloviário justificam a implantação de um sistema com bicicletas compartilhadas complementar ao ônibus atualmente operado.

Como um dos maiores empecilhos para o uso de bicicletas é o esforço físico, a topografia da cidade poderia ser uma restrição ao uso da bicicleta convencional. No entanto, as bicicletas elétricas do tipo pedelec praticamente eliminam esse problema, já que elas possuem um motor elétrico que auxilia a pessoa 
(somente enquanto esta pedala, ou seja, o motor só funciona quando o pedal gira), facilitando o deslocamento de forma considerável. Além de permitir flexibilidade de horários, as bicicletas pedelecs contribuem para a mobilidade urbana e também para a saúde dos(as) estudantes, que, de certo modo, são responsabilidade da universidade. Assim, devido ao contexto apresentado e supondo que haja um público potencial disposto a utilizar bicicletas pedelecs no deslocamento entre as duas áreas do campus, o objetivo deste estudo exploratório é apresentar e discutir os resultados de um procedimento para avaliar a demanda potencial por um sistema de bicicletas pedelecs compartilhadas, supondo a sua implantação no campus de São Carlos da Universidade de São Paulo (USP), com foco no deslocamento entre as duas áreas.

\section{Revisão bibliográfica}

A utilização das bicicletas em sistemas de compartilhamento tem sido tratada como uma das soluções para aprimorar a mobilidade urbana, com foco em pequenos deslocamentos (Boullier \& Crépel, 2014). Hoje, mais de 1100 cidades do mundo têm sistemas em funcionamento (Meddin, 2016), mas sua origem é antiga. A primeira geração é de 1965 e foi criada em Amsterdam. A segunda e terceira gerações surgiram em 1991 e 1996, respectivamente, sendo a última destas criada na Universidade de Portsmouth, na Inglaterra. Atualmente já existem modelos classificados como a quarta geração dos sistemas de compartilhamento. Assim como a terceira geração, são caracterizados pelo uso de avançada tecnologia no gerenciamento do sistema (DeMaio, 2009).

Um dos aprimoramentos da quarta geração em relação à anterior é a utilização de bicicletas pedelecs ao invés das convencionais (Langford et al., 2013, 2015; Cherry et al., 2011). Além das cidades, algumas universidades têm adotado o compartilhamento de bicicletas pedelecs (Langford et al., 2013; Ji et al., 2014), sendo o seu modelo de gestão explanado por DeMaio (2009). Cherry et al. (2011) fizeram uma análise da concepção de um sistema de pedelecs compartilhadas, levando em consideração a estrutura das estações e o manejo das baterias. Ji et al. (2014) fizeram simulações de uso de um sistema com pedelecs compartilhadas na Universidade de Tennessee, em Knoxville, enquanto
Langford et al. (2013) analisaram o primeiro ano de uso do mesmo sistema.

Embora as pedelecs ainda sejam relativamente pouco conhecidas no Brasil, através da Resolução no. 465 de 27 de novembro de 2013, o Conselho Nacional de Trânsito regulamentou as bicicletas elétricas, dividindo-as em duas categorias: ciclomotor e pedal assistido (pedelec). Somente a pedelec pode ser utilizada como uma bicicleta convencional e circular em ciclovias e ciclofaixas, por exemplo, desde que respeitadas algumas obrigações referentes a equipamentos de segurança e características do motor elétrico (CONTRAN, 2013). Atualmente há apenas um sistema de bicicletas pedelecs compartilhadas em funcionamento no Brasil, o qual foi implantado na cidade de São Luiz do Paraitinga/SP (Folha de São Paulo, 2015).

A implantação de um sistema deste tipo requer uma profunda investigação do público-alvo, visto que se trata de um investimento relativamente elevado, já que a aquisição e manutenção das pedelecs é muito maior, quando comparado com os gastos de mesma natureza com bicicletas convencionais. Entretanto, não se deve levar em consideração apenas os custos econômicos, principalmente quando a implantação é feita em uma universidade, local onde tradicionalmente são feitas pesquisas para aprimorar e gerar produtos mais eficientes (Langford et al., 2013), que posteriormente podem ser repassados e aplicados na sociedade.

Um processo bastante comum de investigação do público-alvo é por meio da aplicação de questionários, sejam eles disponibilizados de forma online ou impressa. Quando se trata de um produto pouco conhecido ou novo para o público-alvo, a técnica de preferência declarada, que foi trazida das pesquisas de mercado, se apresenta como uma excelente opção. De acordo com Ortúzar \& Willumsen (2011), a pesquisa de preferência declarada permite que cenários hipotéticos sejam criados, de modo que os(as) respondentes possam opinar a respeito de um modo de transporte que ainda não tenha sido utilizado, como é o caso de bicicletas pedelecs compartilhadas no Brasil. Além disso, permite quantificar quanto cada variável - qualitativa ou não - influencia na escolha. Dentre os métodos de pesquisa de preferência declarada, o mais utilizado na área de transportes é o da escolha preferida (stated choice), no qual apenas uma alternativa deve ser assinalada, mas 
também existem métodos que permitem a ordenação (ranking) e a avaliação (rating) das alternativas (Ortúzar \& Willumsen, 2011).

Outra técnica que também é utilizada é a preferência revelada, que se fundamenta na observação das escolhas reais dos indivíduos. Porém, esse tipo de pesquisa não permite que se quantifique diretamente o peso das variáveis qualitativas na decisão. Além disso, seu custo é significativamente superior ao da pesquisa de preferência declarada (Ortúzar \& Willumsen, 2011).

Maldonado-Hinarejos et al. (2014), Hunt \& Abraham (2007) e Ortúzar et al. (2000) usaram pesquisa de preferência declarada para estimar a demanda potencial pelo modo cicloviário, enquanto Kirner (2006) e Magalhães \& Palhares (2013) usaram o mesmo tipo de pesquisa para caracterizar a demanda pelo transporte cicloviário. Abdelgawad et al. (2016) fizeram uso da preferência declarada para explorar e quantificar as principais barreiras para utilização das bicicletas. Wardman et al. (2007) combinaram pesquisas de preferência revelada e declarada para criar um modelo de estimativa da demanda por bicicletas e Ryley (2006) usou pesquisas de preferência revelada e declarada para avaliar a propensão de usuários(as) de carro, ônibus e a pé mudarem para a bicicleta.

No Brasil, ainda é relativamente escassa a literatura sobre estimação da demanda por bicicletas (conforme discutido em Cadurin, 2016), o que evidencia a necessidade de se aprofundar os estudos em demanda potencial pelo transporte cicloviário. É preciso também avaliar a demanda com base em fatores específicos do local, como as condições meteorológicas, já que o clima pode ser significativamente diferente daquele predominante nos países em que a maioria das pesquisas considerando essas variáveis têm sido feitas. Em virtude disto, o foco do presente estudo está na análise da demanda, por meio de uma modelagem dos dados que permite simular cenários de demanda a partir das inúmeras combinações de valores que as variáveis de entrada (inclusive aspectos da meteorologia) podem assumir.

A partir da discussão de benefícios e limitações do uso de diferentes abordagens (métodos estatísticos e redes neurais artificiais), realizada por Karlaftis \& Vlahogianni (2011) com base em extensa revisão de pesquisas na área de engenharia de transportes, optou-se aqui pelo emprego de redes neurais para a modelagem dos dados proposta. As RNA já foram e ainda são utilizadas na área de transportes, em trabalhos de infraestrutura, planejamento e até economia e políticas de transportes. Em alguns casos, a RNA foi comparada a modelos de regressão múltipla e logit, cuja grande vantagem apresentada pelas RNA foi a maior simplicidade e a interface mais amigável, apresentando resultados satisfatórios (Rodrigues da Silva et al., 2002; Raia Junior, 2000). Já a simulação dos cenários não foi explorada neste trabalho, por estar além do objetivo proposto para o mesmo.

\section{Método}

As etapas de desenvolvimento do trabalho são exibidas na Figura 1.

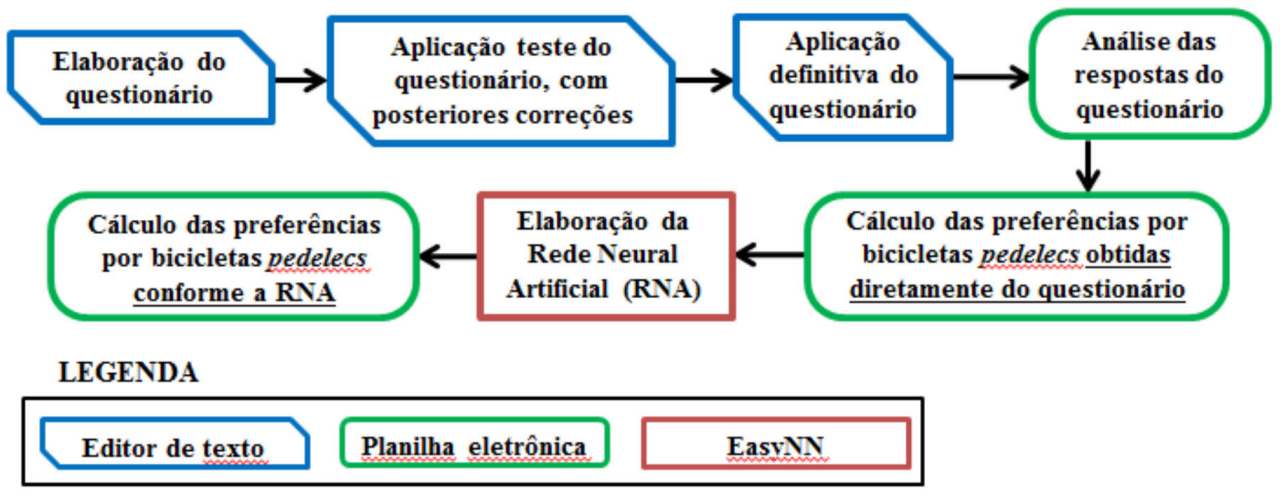

Figura 1 - Síntese das etapas do método utilizado.

Fonte: Autores (2017). 
0 procedimento para avaliação da demanda potencial aqui aplicado se baseia essencialmente em um questionário, com dois blocos de questões. 0 primeiro bloco contém perguntas relacionadas às percepções e atitudes das pessoas a respeito de modos de transporte possíveis de serem utilizados entre as áreas do campus. Já o segundo conjunto de questões foi criado para quantificar a preferência das pessoas por um modo de transporte pouco conhecido do público-alvo (neste caso, as bicicletas pedelecs compartilhadas) para o deslocamento considerado.

Foram formuladas questões relacionadas aos motivos para não usar a bicicleta convencional para se deslocar entre as áreas (somente para quem sabia pedalar e não usava a bicicleta convencional neste deslocamento), à experiência com meios de transporte já utilizados no percurso considerado (respondida por todos), ao tempo médio gasto no deslocamento (somente para quem usava carro e bicicleta), ao tempo máximo aceitável para deslocamento (respondida por todos), às razões para não usufruir do ônibus ofertado pela USP (somente para quem não usava o ônibus nesse deslocamento) e à rejeição aos meios de transporte (respondida por todos).

As perguntas sobre os motivos para não usar a bicicleta convencional, sobre a experiência com meios de transporte já utilizados e sobre as razões para não utilizar o ônibus ofertado pela USP (todas com base no percurso considerado) foram analisadas de acordo com o método dos intervalos sucessivos, procedimento descrito e adotado por Providelo \& Sanches (2010). Originalmente, a primeira pergunta possuía oito fatores, os quais os(as) respondentes deveriam ordenar de 1 a 8 , sendo o número 8 associado ao fator mais importante e o número 1 ao menos importante (em relação à decisão de não usar a bicicleta convencional no deslocamento entre as áreas do campus). Na segunda e na terceira pergunta, os(as) respondentes deveriam avaliar cada fator conforme uma escala fornecida. Na segunda pergunta (experiência com meios de transporte já utilizados) a escala era de 1 a 4 , sendo o número 4 associado a "muito satisfeito" e o número 1 a "muito insatisfeito". Na terceira pergunta, a escala era de 1 a 3 , sendo o número 3 associado a "extremamente importante - crucial", o número 2 a "muito importante" e o número 1 a "pouco importante" (em relação à decisão de não usar o ônibus da USP no deslocamento entre as áreas do campus).
Assim, após a coleta de dados com base nas escalas fornecidas no questionário, o método dos intervalos sucessivos pôde ser aplicado neste trabalho, permitindo a calibração de nova escala que transcrevesse a distribuição das respostas para as três perguntas citadas. Além disso, o procedimento também permitiu a visualização da importância de cada fator após a calibração da nova escala.

Em relação às perguntas sobre a preferência por pedelec compartilhada ou o ônibus da USP (direcionadas somente para quem sabia pedalar), dois textos introdutórios foram utilizados para este conjunto de perguntas, um apresentando as bicicletas elétricas e outro explicando o que seria o sistema de compartilhamento de bicicletas considerado. 0 ônibus da USP e as bicicletas pedelecs compartilhadas foram então comparados no que tange à disponibilidade de horários, ao custo para o(a) usuário(a) e ao tempo de viagem, com base na Figura 2.
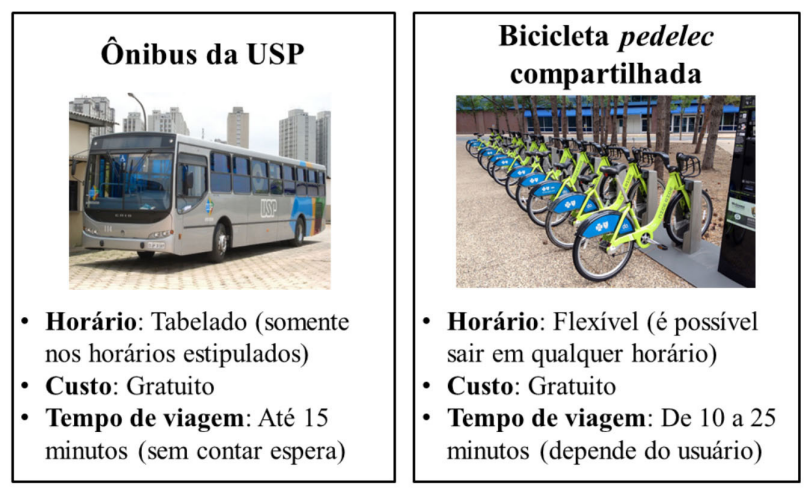

Figura 2 - Comparação de características entre o ônibus da USP e o sistema de bicicletas pedelecs compartilhadas.

Fonte: Autores (2017).

Além das características fixadas para cada um dos sistemas, citadas na Figura 2, foram feitas combinações de três aspectos:

- Ciclovias e/ou ciclofaixas entre as áreas: caracterizadas em dois níveis, presença ou ausência total;

- Ponto de ônibus da USP: caracterizado em dois níveis, cheio ou vazio;

- Condições meteorológicas: caracterizadas em quatro níveis, sendo sol e frio (aproximadamente $18^{\circ} \mathrm{C}$ ), sol e temperatura moderada (por volta de $26^{\circ} \mathrm{C}$ ), sol e calor (cerca de 34 ${ }^{\circ} \mathrm{C}$ ) e nublado e possibilidade de chuva. 
As condições meteorológicas e a infraestrutura para bicicletas estão entre os principais fatores que influenciam a demanda pelo transporte cicloviário (Godefroy \& Morency, 2012; Hunt \& Abraham, 2007). No caso da meteorologia, as condições de temperatura foram adotadas de acordo com as temperaturas máximas diárias registradas na cidade de São Carlos/ SP, no período de 2011 a 2015. A condição de chuva (isto é, dia chuvoso) não foi inserida no questionário para evitar um número ainda maior de combinações geradas, o que tende a cansar o(a) respondente. Já o ponto de ônibus da USP, trata-se de uma variável específica deste contexto de pesquisa. Como supôs-se que os pontos de retirada das bicicletas estariam próximos aos pontos de ônibus e a origem/destino seria a mesma para os dois meios de transporte, trata-se de uma variável relevante para este caso, visto que os dois sistemas seriam complementares.

A partir das combinações desses aspectos foi possível gerar 16 cenários (fatorial completo), os quais foram apresentados aos(às) respondentes utilizando a Figura 3, com base na técnica de preferência declarada e escolha preferida (stated choice). Para cada um dos cenários, os(as) respondentes deveriam apontar o modo de sua preferência (ônibus ou pedelec).

\begin{tabular}{|c|c|c|c|c|c|c|c|}
\hline \multirow{3}{*}{$\begin{array}{c}\text { Ponto de } \\
\text { onnibus }\end{array}$} & [1 & \multirow{2}{*}{\multicolumn{2}{|c|}{$\begin{array}{c}\text { Considere } \\
\text { presença total } \\
\text { de ciclovias } \\
\text { e/ou ciclofaixas } \\
\text { entre as Áreas } \\
\text { do Campus } \\
\text { ESCOLHA }\end{array}$}} & \multicolumn{4}{|c|}{$\begin{array}{c}\text { Considere } \\
\text { ausência total } \\
\text { de ciclovias e/ou } \\
\text { ciclofaixas entre } \\
\text { as Áreas do } \\
\text { Campus }\end{array}$} \\
\hline & \multirow{2}{*}{$\begin{array}{c}\text { Condições } \\
\text { meteorológicas }\end{array}$} & & & \multirow{2}{*}{$\begin{array}{c}\text { Ponto de } \\
\text { onibus }\end{array}$} & \multirow{2}{*}{$\begin{array}{c}\text { Condições } \\
\text { meteorológicas }\end{array}$} & \multicolumn{2}{|c|}{ ESCOLHA } \\
\hline & & \multirow[t]{2}{*}{\begin{tabular}{|l|} 
Ônibus \\
\end{tabular}} & \multirow[t]{2}{*}{ Pedelec } & & & \begin{tabular}{|l|} 
Ônibus \\
\end{tabular} & Pedelec \\
\hline Cheio & Sol, calor $\left(\approx 34^{\circ} \mathrm{C}\right)$ & & & Cheio & Sol, calor $\left(\approx 34^{\circ} \mathrm{C}\right)$ & & \\
\hline Cheio & Sol, frio $\left(\approx 18^{\circ} \mathrm{C}\right)$ & & & Cheio & Sol, frio $\left(\approx 18^{\circ} \mathrm{C}\right)$ & & \\
\hline Cheio & $\begin{array}{c}\text { Nublado, } \\
\text { possibilidade chuva }\end{array}$ & & & Cheio & $\begin{array}{c}\text { Nublado, } \\
\text { possibilidade chuva }\end{array}$ & & \\
\hline Cheio & $\begin{array}{c}\text { Sol, temperatura } \\
\text { moderada }\left(\approx 26^{\circ} \mathrm{C}\right)\end{array}$ & & & Cheio & $\begin{array}{c}\text { Sol, temperatura } \\
\text { moderada }\left(\approx 26^{\circ} \mathrm{C}\right)\end{array}$ & & \\
\hline Vazio & Sol, calor $\left(\approx 34^{\circ} \mathrm{C}\right)$ & & & Vazio & Sol, calor $\left(\approx 34^{\circ} \mathrm{C}\right)$ & & \\
\hline Vazio & Sol, frio $\left(\approx 18^{\circ} \mathrm{C}\right)$ & & & Vazio & Sol, frio $\left(\approx 18^{\circ} \mathrm{C}\right)$ & & \\
\hline Vazio & $\begin{array}{c}\text { Nublado, } \\
\text { possibilidade chuva }\end{array}$ & & & Vazio & $\begin{array}{c}\text { Nublado, } \\
\text { possibilidade chuva }\end{array}$ & & \\
\hline Vazio & $\begin{array}{c}\text { Sol, temperatura } \\
\text { moderada }\left(\approx 26^{\circ} \mathrm{C}\right)\end{array}$ & & & Vazio & $\begin{array}{c}\text { Sol, temperatura } \\
\text { moderada }\left(\approx 26^{\circ} \mathrm{C}\right)\end{array}$ & & \\
\hline
\end{tabular}

Figura 3 - Composição dos cenários para a escolha do modo preferido. Fonte: Autores (2017).

Em relação à aplicação do questionário, o qual foi impresso, primeiramente foi feito um teste com 74 alunos(as) de graduação, matriculados na disciplina "Planejamento e Análise de Sistemas de Transportes", regularmente ministrada para o curso de Engenharia Civil da Escola de Engenharia de São Carlos (EESC), no segundo semestre do terceiro ano. Após a incorporação de algumas sugestões e eventuais correções, o questionário pôde ser aplicado junto ao público-alvo, que foi composto por alunos(as) de graduação e pós-graduação que frequentam a Área 2 do campus. Para essa aplicação, houve a colaboração dos(as) mesmos(as) alunos(as) que haviam participado da fase de teste. Os(as) aplicadores(as) foram instruídos(as) em relação à abordagem a ser adotada e atuaram sob coordenação do primeiro autor. Alguns(mas) optaram pela aplicação dentro das salas de aula da Área 2, enquanto outros(as) abordaram as pessoas dentro do campus (inclusive no próprio ponto de ônibus). 0 tempo gasto para responder ao questionário foi, em média, de 15 minutos.

Após a obtenção das preferências dos(as) participantes, por meio das respostas da Figura 3, foi 
treinada uma rede neural artificial (RNA) através do software EasyNN (desenvolvido e comercializado por Stephen Wolstenholme, Inglaterra), que emprega redes MLP (multilayer perceptron) com até três camadas ocultas e um algoritmo de treinamento do tipo backpropagation. As variáveis foram inseridas de acordo com a Tabela 1. Desse modo, na camada de entrada foram utilizados seis neurônios para caracterizar as variáveis da Tabela 1: ciclovia, ponto, calor, moderado, frio e possibilidade de chuva. Foi utilizada apenas uma camada intermediária, a qual foi composta por seis neurônios. Em relação às etapas de construção da RNA, foram utilizados 50\% dos dados para treinamento, $25 \%$ para validação e os demais $25 \%$ para teste. Para todas as etapas, os dados foram selecionados de maneira aleatória e foram realizados 83560 ciclos de treinamento/validação. Em seguida, foram calculadas as preferências entre o ônibus da USP e as bicicletas pedelecs, conforme cada cenário.

Tabela 1 - Valores dos níveis das variáveis para inserção no software EasyNN

\begin{tabular}{cccccccc}
\hline Valor & Escolha & $\begin{array}{c}\text { Ciclovia } \\
\text { Ciclofaixa }\end{array}$ & $\begin{array}{c}\text { Ponto } \\
\text { Onibus } \\
\text { USP }\end{array}$ & $\begin{array}{c}\text { Sol } \\
\text { Calor }\end{array}$ & $\begin{array}{c}\text { Sol } \\
\text { Moderado }\end{array}$ & $\begin{array}{c}\text { Sol } \\
\text { Frio }\end{array}$ & $\begin{array}{c}\text { Nublado } \\
\text { Possibilidade de } \\
\text { chuva }\end{array}$ \\
\hline 0 & Onibus & Ausência & Vazio & & & & \\
1 & Pedelec & Presença & Cheio & $X$ & $X$ & $X$ & $X$ \\
\hline
\end{tabular}

Fonte: Autores (2017).

\section{Resultados}

No total, 400 questionários foram respondidos, sendo 369 por alunos(as) de graduação, 28 por alunos(as) de pós-graduação, além de uma pós-doutoranda, uma funcionária técnica-administrativa e uma resposta em branco, que, por não se enquadrarem no perfil do público-alvo, foram descartados. Em relação ao gênero e vínculo com a universidade, a Tabela 2 apresenta os valores obtidos.

Tabela 2 - Gênero e vínculo com a universidade das pessoas que responderam ao questionário

\begin{tabular}{cccc}
\hline Gênero & Graduação & Pós-graduaç̃ão & Total \\
\hline Feminino & $110(27,71 \%)$ & $13(3,27 \%)$ & $123(30,98 \%)$ \\
Masculino & $259(65,24 \%)$ & $15(3,78 \%)$ & $274(69,02 \%)$ \\
Total & $369(92,95 \%)$ & $28(7,05 \%)$ & $397(100,00 \%)$ \\
\hline
\end{tabular}

Obs.: Os valores percentuais são em relaçã̃o ao total geral de respondentes. Fonte: Autores (2017).

A percepção dos(as) respondentes quanto ao tempo máximo aceitável para o deslocamento entre as áreas do campus pode ser visualizada na Tabela 3. Nota-se que cerca de $50 \%$ das pessoas toleram viagens que durem até 15 minutos. Quase 25\% responderam que 20 minutos é um tempo aceitável, enquanto menos de $15 \%$ só aceitam viagens que demorem até 10 minutos.

Tabela 3 - Tempo máximo aceitável para 0 deslocamento entre as áreas do campus

\begin{tabular}{ccc}
\hline Tempo máximo aceitável & Quantidade & \% do Total \\
\hline 10 min & 53 & 13,35 \\
15 min & 198 & 49,87 \\
20 min & 94 & 23,68 \\
25 min & 20 & 5,04 \\
30 min & 22 & 5,54 \\
Total & 397 & 100,00 \\
\hline
\end{tabular}

Fonte: Autores (2017).

Os resultados do tempo gasto por pessoas que se deslocam com carro (como motorista ou passageiro) e bicicleta convencional podem ser vistos nas Tabelas 4 e 5, respectivamente. Mais da metade das pessoas que usam o carro gastam até 10 minutos na viagem entre as duas áreas. Em relação à bicicleta, a maior parte (aproximadamente 35\%) gasta entre 10 a 15 minutos e quase $24 \%$ usa mais de 25 minutos. Mais da metade das pessoas que pedalam até a Área 2 
utiliza no máximo 20 minutos neste trajeto. É interessante notar como a diversidade de tempo de viagem é mais discrepante para quem usa a bicicleta.

Tabela 4 - Tempo de viagem, com carro (como motorista ou passageiro), no deslocamento entre as áreas do campus

\begin{tabular}{ccc}
\hline Tempo de viagem (carro) & Quantidade & \% do Total \\
\hline Até $10 \mathrm{~min}$ & 152 & 57,58 \\
10 a $15 \mathrm{~min}$ & 108 & 40,91 \\
Mais de $15 \mathrm{~min}$ & 4 & 1,52 \\
Total & 264 & 100,00 \\
\hline
\end{tabular}

Fonte: Autores (2017)

Tabela 5 - Tempo de viagem, com bicicleta convencional, no deslocamento entre as áreas do campus

\begin{tabular}{ccc}
\hline Tempo de viagem (bicicleta) & Quantidade & \% do Total \\
\hline Até 10 min & 2 & 5,88 \\
10 a 15 min & 12 & 35,29 \\
15 a 20 min & 5 & 14,71 \\
20 a 25 min & 7 & 20,59 \\
Mais de 25 min & 8 & 23,53 \\
Total & 34 & 100,00 \\
\hline
\end{tabular}

Fonte: Autores (2017)
Os motivos para não utilizar a bicicleta convencional como meio de transporte entre as áreas são apresentados na Tabela 6, sendo o número zero atribuído para a menor importância e o número um para a maior importância (em relação à decisão de não usar a bicicleta convencional).

Considerando a amostra completa, os aspectos que mais afastam os(as) respondentes das bicicletas convencionais como meio de transporte entre as áreas são as condições meteorológicas $(1,00)$, o esforço físico $(0,93)$, o tempo de viagem $(0,88)$ e a ausência de ciclovias e/ou ciclofaixas $(0,88)$. Os menos impactantes são a aceitabilidade social $(0,00)$ e a ausência de bicicletários $(0,36)$.

Entre os gêneros feminino e masculino é interessante notar como a ausência de ciclovias/ciclofaixas impacta mais no feminino $(1,00)$ do que no masculino $(0,82)$. A experiência em outros locais demonstra que, após a implantação de ciclovias/ciclofaixas em uma via, o número de mulheres circulando com bicicleta pela mesma via tende a aumentar significativamente (Garrard et al., 2008; Pucher et al., 2010; Vá de Bike, 2015). Outra diferença bastante relevante é vista no item "segurança em relação a assaltos", que também aflige mais às respondentes do gênero feminino $(0,86)$ do que aos do gênero masculino $(0,64)$.

Tabela 6 - Importância dos motivos para a decisão de não utilizar a bicicleta convencional no deslocamento entre as áreas do campus, sendo o número zero associado a menor importância e o número um a maior importância

\begin{tabular}{|c|c|c|c|c|c|c|c|}
\hline \multirow[b]{2}{*}{ Característica } & \multicolumn{6}{|c|}{ Importância } & \multirow[b]{2}{*}{$\begin{array}{l}\text { Bici. Não } \\
\text { Transp.** }\end{array}$} \\
\hline & Completo & Fem. & Masc. & Grad. & Pós-grad. & Bici. Transp.* $^{*}$ & \\
\hline Esforçco físico/Cansaço & 0,93 & 0,87 & 0,94 & 0,94 & 0,71 & 0,96 & 0,92 \\
\hline Tempo de viagem & 0,88 & 0,81 & 0,91 & 0,89 & 0,79 & 0,90 & 0,88 \\
\hline Ausência de ciclovias e/ou ciclofaixas & 0,88 & 1,00 & 0,82 & 0,90 & 0,73 & 0,81 & 0,90 \\
\hline Ausência de bicicletários & 0,36 & 0,32 & 0,38 & 0,36 & 0,40 & 0,39 & 0,36 \\
\hline Aceitabilidade social (imagem da bicicleta) & 0,00 & 0,00 & 0,00 & 0,00 & 0,00 & 0,00 & 0,00 \\
\hline Segurança em relação a assaltos & 0,71 & 0,86 & 0,64 & 0,71 & 0,75 & 0,52 & 0,75 \\
\hline Condiçōes meteorológicas & 1,00 & 0,97 & 1,00 & 1,00 & 1,00 & 1,00 & 1,00 \\
\hline Material transportado & 0,80 & 0,90 & 0,76 & 0,79 & 0,84 & 0,65 & 0,82 \\
\hline
\end{tabular}

* Usuários(as) que utilizam a bicicleta como meio de transporte (mas não entre as áreas).

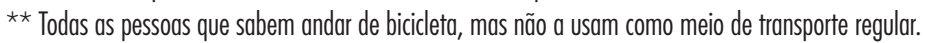
Fonte: Autores (2017).

Quando comparados os grupos de alunos(as) de graduação e de pós-graduação, as características que apresentaram maiores discrepâncias foram a de esforço físico $(0,94$ e 0,71, respectivamente), a de ausência de ciclovias e/ou ciclofaixas $(0,90$ e 0,73 , respectivamente) e a de tempo de viagem $(0,89$ e 0,79 , respectivamente). 
A característica de esforço físico impacta mais quem usa a bicicleta convencional como meio de transporte, em relação a quem não usa $(0,96$ e 0,92, respectivamente). Por outro lado, a segurança relacionada a assaltos, o material transportado e a ausência de ciclovias e/ou ciclofaixas impactam muito menos quem adota o modo cicloviário como transporte $(0,52,0,65$ e 0,81 para estes e $0,75,0,82$ e 0,90 para quem não faz esse uso).

A Tabela 7 apresenta os motivos que levam os(as) respondentes a não usarem o ônibus operado pela USP na ligação entre as áreas do campus. O número zero está associado a menor importância e o número um a maior importância (em relação à decisão de não usar o ônibus da USP).

Tabela 7 - Importância dos motivos para a decisão de não ưtilizar o ônibus operado pela USP na ligação entre as áreas do campus, sendo o número zero associado a menor importância e o número um a maior importância

\begin{tabular}{|c|c|c|c|c|c|c|c|}
\hline \multirow[b]{2}{*}{ Característica } & \multicolumn{7}{|c|}{ Importância } \\
\hline & Completo & Fem. & Masc. & Grad. & $\begin{array}{l}\text { Pós- } \\
\text {-grad. }\end{array}$ & Bici. Transp.* & $\begin{array}{l}\text { Bici. Não } \\
\text { Transp.** }\end{array}$ \\
\hline Tempo de viagem dentro do ônibus & 0,33 & 0,32 & 0,30 & 0,36 & 0,12 & 0,36 & 0,27 \\
\hline Distância de caminhada até os pontos & 0,59 & 0,35 & 0,69 & 0,62 & 0,31 & 0,62 & 0,55 \\
\hline Horários de partida disponíveis & 1,00 & 1,00 & 1,00 & 1,00 & 1,00 & 1,00 & 1,00 \\
\hline Não iniciar a viagem no horário que eu quiser & 0,69 & 0,66 & 0,69 & 0,72 & 0,38 & 0,86 & 0,65 \\
\hline Não ter mais pontos de embarque/desembarque & 0,44 & 0,48 & 0,41 & 0,50 & 0,11 & 0,62 & 0,41 \\
\hline Condiçōes meteorológicas & 0,47 & 0,53 & 0,41 & 0,51 & 0,12 & 0,56 & 0,39 \\
\hline Material transportado & 0,34 & 0,51 & 0,23 & 0,37 & 0,12 & 0,20 & 0,31 \\
\hline Lotação do ônibus & 0,82 & 0,97 & 0,77 & 0,84 & 0,62 & 0,86 & 0,81 \\
\hline Segurança durante a viagem & 0,18 & 0,29 & 0,08 & 0,21 & 0,00 & 0,00 & 0,17 \\
\hline Segurança na caminhada até os pontos & 0,38 & 0,57 & 0,26 & 0,39 & 0,37 & 0,20 & 0,38 \\
\hline Falta de informação sobre o sistema de ônibus & 0,00 & 0,00 & 0,00 & 0,00 & 0,01 & 0,02 & 0,00 \\
\hline Estrutura dos pontos & 0,25 & 0,19 & 0,26 & 0,27 & 0,19 & 0,29 & 0,20 \\
\hline Qualidade dos ônibus & 0,38 & 0,32 & 0,40 & 0,42 & 0,19 & 0,41 & 0,35 \\
\hline
\end{tabular}

* Usuários(as) que utilizam a bicicleta como meio de transporte (mas não entre as áreas).

${ }^{* *}$ Todas as pessoas que sabem andar de bicicleta, mas não a usam como meio de transporte regular.

Fonte: Autores (2017).

Para a amostra completa, é possível notar que os aspectos mais relevantes para os(as) respondentes não utilizarem o ônibus ofertado pela USP são os horários de partida disponíveis $(1,00)$, a lotação do ônibus $(0,82)$, ter que iniciar a viagem somente nos horários tabelados $(0,69)$ e a distância de caminhada até os pontos $(0,59)$. Por outro lado, um bom sinal é que os(as) respondentes aparentam ter conhecimento sobre o funcionamento do sistema de ônibus da USP (valor 0,00 na Tabela 7, ou seja, menor importância).

As diferenças mais significativas entre os gêneros masculino e feminino são a lotação do ônibus $(0,77$ e 0,97 , respectivamente), a segurança na 
caminhada até os pontos $(0,26$ e 0,57 , respectivamente) e a distância de caminhada até os pontos $(0,69$ e 0,35 , respectivamente).

No caso dos(as) respondentes de graduação e pós-graduação, as diferenças mais relevantes são decorrentes dos horários tabelados ("não iniciar a viagem no horário que eu quiser"), lotação dos ônibus e distância de caminhada até os pontos $(0,72$, 0,84 e 0,62 para graduação e $0,38,0,62$ e 0,31 para pós-graduação).

Entre as pessoas que usam a bicicleta convencional como meio de transporte e as que não usam, as maiores diferenças observadas ocorrem para os horários tabelados $(0,86$ e 0,65 , respectivamente) e a quantidade de pontos de embarque/desembarque $(0,62$ e 0,41 , respectivamente).

A respeito dos meios de transporte que os(as) respondentes utilizam ou já utilizaram para realizar os deslocamentos entre as áreas do campus, os resultados são exibidos na Tabela 8 , sendo o número zero associado à menor importância (pior avaliado) e o número um associado à maior importância (melhor avaliado).

Tabela 8 - Importância dos meios de transporte, sendo o número zero associado à menor importância (pior avaliado) e o número um à maior importância (melhor avaliado)

\begin{tabular}{cc}
\hline Meio de transporte & Importância \\
\hline Ônibus da USP & 0,68 \\
Ônibus municipal & 0,30 \\
Carro & 1,00 \\
Moto & 0,47 \\
Bicicleta convencional & 0,39 \\
A pé & 0,00 \\
\hline
\end{tabular}

Fonte: Autores (2017).

Nota-se que o meio de transporte com pior avaliação é o modo a pé. Merece destaque o ônibus da USP (segunda melhor avaliação, com importância de 0,68$)$, que atualmente é a única opção ofertada pela universidade para realizar o deslocamento entre as áreas. A bicicleta convencional $(0,39)$ apresentou avaliação melhor do que a do ônibus municipal $(0,30)$, cuja operação na época era realizada por uma empresa privada, em regime de concessão.
O grau de rejeição a cada um dos meios de transporte, ou seja, qual(is) opção(es) nunca seria(m) utilizada(s) pelos(as) respondentes para se deslocar entre as áreas do campus, pode ser visto na Figura 4.

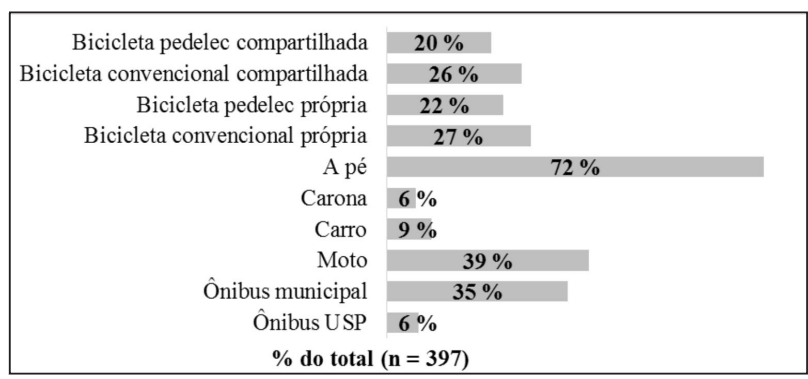

Figura 4 - Rejeição aos meios de transporte.

Fonte: Autores (2017).

O ônibus da USP e a carona de carro apresentaram valores baixos de rejeição (ambos de $6 \%$ ), inferiores ao valor do carro (9\%). 0 ônibus municipal apresenta rejeição relativamente alta (35\%), mas a maior rejeição é ao modo a pé, com um valor de $72 \%$.

As bicicletas convencional e pedelec próprias apresentaram, respectivamente, $27 \%$ e $22 \%$ de rejeição. Em relação às mesmas bicicletas citadas, mas numa situação de compartilhamento provido pela universidade, os valores de rejeição caíram para $26 \%$ e $20 \%$, respectivamente. Apesar da diferença ser muito pequena, é possível notar que as pessoas se veem mais propensas a utilizar as bicicletas em um sistema de compartilhamento do que adquirir uma própria, embora a experiência demonstre, segundo Midgley (2009), que as pessoas se sentem mais estimuladas a pedalar após experimentarem uma bicicleta compartilhada, o que pode culminar na aquisição de uma.

Em relação às preferências por bicicletas pedelecs compartilhadas ou ônibus, a arquitetura da RNA treinada com os dados obtidos pela aplicação do questionário (consideradas apenas as respostas das pessoas que sabem pedalar e que utilizam o ônibus da USP, o que corresponde a 252 pessoas) pode ser vista na Figura 5. Neste caso, a RNA acertou mais de $80 \%$ das respostas para uma parcela de dados não conhecidos previamente pela rede. 


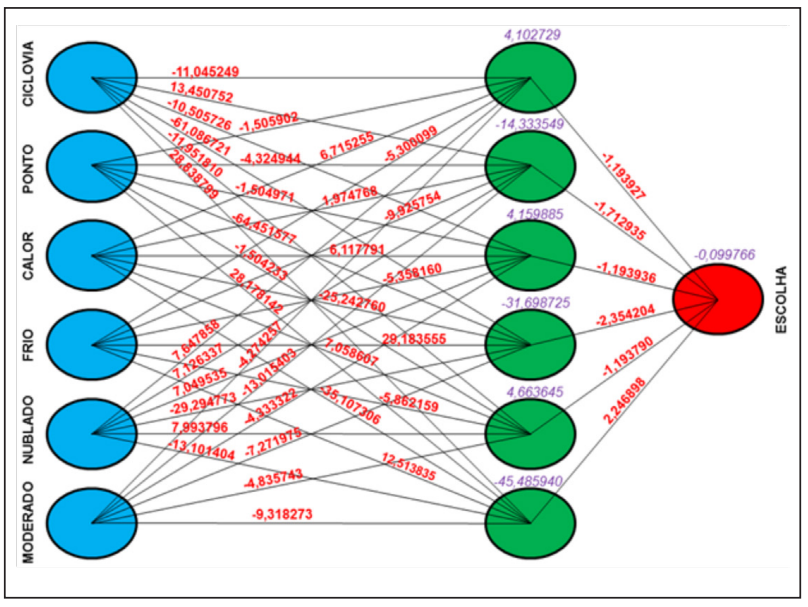

Figura 5 - Arquitetura da RNA treinada com os dados da preferência declarada.

Fonte: Autores (2017).

As preferências, obtidas através da RNA treinada, podem ser vistas na Figura 6 para os 16 cenários da pergunta de preferência declarada.

É possível notar que as condições "presença total de ciclovias/ciclofaixas" e "ponto do ônibus cheio" favorecem consideravelmente a escolha da bicicleta pedelec. Considerando as situações que envolvem frio, com ciclovias/ciclofaixas e ponto de ônibus cheio, 90\% dos(as) respondentes escolheram a bicicleta pedelec. No entanto, quando a condição do ponto se tornou vazio e se manteve a presença de ciclovias/ciclofaixas, o valor foi reduzido para $48 \%$. Sem ciclovias/ciclofaixas e com ponto cheio o valor reduziu pouco, para $42 \%$. Mas com a combinação sem ciclovias/ciclofaixas e com ponto vazio o valor diminuiu de forma significativa, para $25 \%$.

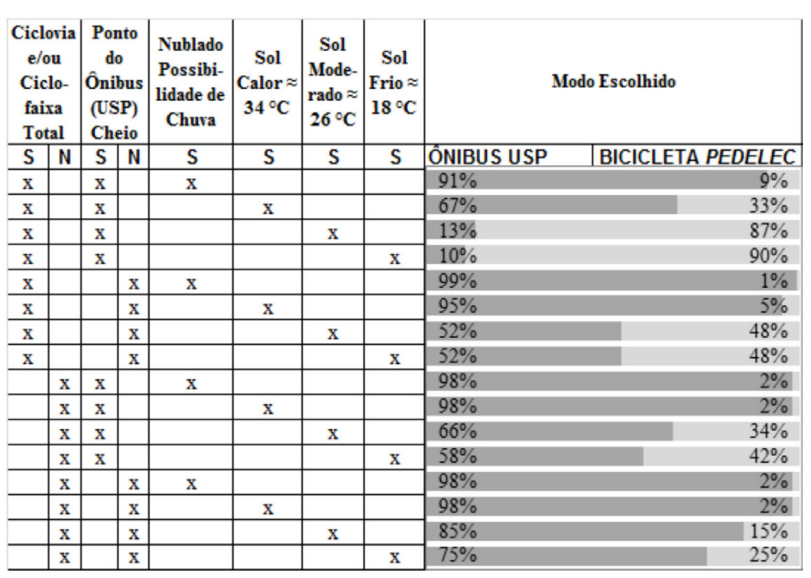

Figura 6 - Preferências por bicicletas pedelecs compartilhadas, quando comparadas ao ônibus operado pela USP, para os 16 cenários.

Fonte: Autores (2017).
Em relação às condições meteorológicas, as mais favoráveis para a escolha da pedelec são o frio e a temperatura moderada que, na situação mais desfavorável possível (sem ciclovias/ciclofaixas e ponto de ônibus vazio), possuem preferência de $25 \%$ e $15 \%$ dos(as) respondentes, respectivamente. $\mathrm{Na}$ situação mais favorável possível (com ciclovias/ ciclofaixas e ponto de ônibus cheio), esses valores ascendem para $90 \%$ e $87 \%$, respectivamente. Por outro lado, a condição de tempo nublado e com possibilidade de chuva apresentou, de forma geral, os menores valores de escolha da bicicleta pedelec, seguido da condição de calor.

\section{Conclusões}

Diante do cenário avaliado, a grande rejeição pelo modo a pé e pelo ônibus coletivo municipal, que à época operava sob responsabilidade de uma empresa privada, são os dados mais críticos. Dentre os aspectos que mais pesam na decisão de não usar o ônibus da USP, a lotação e o fato de não poder iniciar a viagem a qualquer momento são favoráveis ao uso da bicicleta, seja ela convencional ou pedelec. Entre os fatores mais impactantes para não se usar as bicicletas convencionais estão o esforço físico, as condições meteorológicas, o tempo de viagem e a ausência de ciclovias/ciclofaixas. 0 esforço físico e o tempo de viagem são consideravelmente reduzidos com o uso da bicicleta pedelec em relação à convencional, devido ao auxílio proveniente do motor elétrico. Isto contribuiria para a escolha, no hipotético sistema de compartilhamento de bicicletas, da pedelec ao invés da convencional. Vale lembrar que cerca de $50 \%$ dos(as) respondentes avaliaram como 15 minutos o tempo máximo aceitável para o deslocamento entre as áreas, enquanto quase 25\% julgaram 20 minutos como o máximo aceitável.

Em relação à preferência declarada, a escolha das variáveis de condições meteorológicas e situação de ciclovias/ciclofaixas para avaliar a preferência entre bicicletas pedelecs compartilhadas e o ônibus da USP se mostrou adequada, visto que estas variáveis estão entre os fatores mais impactantes para não se usar bicicletas convencionais. A condição de lotação do ponto de ônibus da USP também demonstrou ser uma escolha adequada como variável. Quando há suposição de existência de ciclovias e/ou ciclofaixas 
em toda a extensão entre as duas Áreas do campus da USP de São Carlos e o ponto de ônibus da USP é considerado cheio, há expressivo aumento da probabilidade de escolha da bicicleta pedelec, em relação às situações em que as duas variáveis são consideradas de maneira oposta (ciclovias/ciclofaixas ausentes e ponto vazio). Mais detalhes podem ser consultados em Cadurin (2016).

Por fim, é importante dizer que o procedimento apresentado pode ser aplicado em outros estudos, desde que as preferências entre modos de transporte sejam obtidas conforme o público e objetivo que se almeja. Os autores recomendam a utilização de atributos que abordem ciclovias/ciclofaixas e condições meteorológicas, tal como elaborado neste trabalho. No que tange à(s) outra(s) variável(eis) da preferência declarada, o(a) pesquisador(a) deverá se atentar para características relevantes do estudo em questão.

\section{Agradecimentos}

Osautoresagradecem ao CNPq(Conselho Nacional de Desenvolvimento Científico e Tecnológico), à FAPESP (Fundação de Amparo à Pesquisa do Estado de São Paulo) e à Universidade de São Paulo, pelo apoio para a realização da pesquisa.

\section{Referências}

Abdelgawad, H., Mahmoud, M. S., \& Kinawy, S. N. (2016). Understanding cycling behavior and barriers to cycling in Egypt. In TRB 95th Annual Meeting Compendium of Papers. Washington, DC, EUA: TRB.

Boullier, D. E., \& Crépel, M. (2014). Vélib and data: a new way of inhabiting the city. Revista Brasileira de Gestão Urbana, 6(1), 47-56.

Cadurin, L. D. P. (2016). Demanda potencial para um sistema de compartilhamento de bicicletas pedelecs: o caso de um campus universitário (Dissertação de Mestrado). Universidade de São Paulo, São Carlos, Brasil.

Cherry, C., Worley, S., \& Jordan, D. (2011). Electric bike sharing: system requirements and operational concepts. In TRB 90th Annual Meeting Compendium of Papers. Washington, DC, EUA: TRB.
Conselho Nacional de Trânsito - CONTRAN. (2013). Resolução n. 465 de 27 de Novembro de 2013. Recuperado em 02 de novembro de 2016, de http://www.denatran. gov.br/download/Resolucoes/Resolucao4652013.pdf

DeMaio, P. (2009). Bike-sharing: history, impacts, models of provision, and future. Journal of Public Transportation, 12(4), 41-56.

Folha de São Paulo. (2015). Bicicletas elétricas ajudam a vencer ladeiras em São Luiz do Paraitinga. Recuperado em 02 de novembro de 2016, de http://www1.folha.uol.com. br/cotidiano/2015/06/1638493-bicicletas-eletricas-ajudam-a-vencer-ladeiras-em-sao-luiz-do-paraitinga. shtml

Garrard, J., Rose, G., \& Lo, S. K. (2008). Promoting transportation cycling for women: the role of bicycle infrastructure. Preventive Medicine, 46(1), 55-59.

Godefroy, F., \& Morency, C. (2012). Estimating latent cycling trips in Montreal, Canada. Transportation Research Record: Journal of the Transportation Research Board, 2314, 120-128.

Hunt, J. D., \& Abraham, J. E. (2007). Influences on bicycle use. Transportation, 34, 453-470.

Ji, S., Cherry, C. R., Han, L. D., \& Jordan, D. A. (2014). Electric bike sharing: simulation of user demand and system availability. Journal of Cleaner Production, 85, 250-257.

Karlaftis, M. G., \& Vlahogianni, E. I. (2011). Statistical methods versus neural networks in transportation research: differences, similarities and some insights. Transportation Research Part C: Emerging Technologies, 19, 387-399.

Kirner, J. (2006). Proposta de um método para a definição de rotas cicláveis em áreas urbanas (Dissertação de Mestrado). Universidade Federal de São Carlos, São Carlos, Brasil.

Langford, B. C., Chen, J., \& Cherry, C. R. (2015). Risky riding: naturalistic methods comparing safety behavior from conventional bicycle riders and electric bike riders. Accident Analysis \& Prevention, 82, 220-226.

Langford, B. C., Cherry, C., Yoon, T., Worley, S., \& Smith, D. (2013). North America's first e-bikeshare: a year of experience. Transportation Research Record: Journal of the Transportation Research Board, 2387, 120-128. 
Magalhães, J. R. L., \& Palhares, D. A. G. (2013). Utilização do método de preferência declarada para caracterização da demanda pelo transporte cicloviário em Montes Claros/MG. In Anais do XXVII Congresso de Pesquisa e Ensino em Transportes. Belém, Bahia, Brasil: ANPET.

Maldonado-Hinarejos, R., Sivakumar, A., \& Polak, J. W. (2014). Exploring the role of individual attitudes and perceptions in predicting the demand for cycling: a hybrid choice modelling approach. Transportation, 41, $1287-1304$

Meddin, R. (2016). The bike-sharing world map. Recuperado em 02 de novembro de 2016, de www.bikesharingmap.com

Midgley, P. (2009). The role of smart bike-sharing systems in urban mobility. Journeys - Sharing Urban Transport Solutions, 2, 23-31.

Oliveira, A. M. (2015). Um índice para o planejamento de mobilidade com foco em grandes polos geradores de viagens: desenvolvimento e aplicação em um campus universitário - Apêndice C (Dissertação de Mestrado). Universidade de São Paulo, São Carlos, Brasil.

Ortúzar, J. D., Iacobelli, A., \& Valeze, C. (2000). Estimating demand for a cycle-way network. Transportation Research Part A: Policy and Practice, 34(5), 353-373.

Ortúzar, J. D., \& Willumsen, L. G. (2011). Modelling transport ( $4 \underline{a}$ ed.). Chichester, Reino Unido: John Wiley \& Sons Ltd.

Providelo, J. K., \& Sanches, S. P. (2010). Roadway and traffic characteristics for bicycling. In 12th World Conference on Transport Research. Lisboa, Portugal: WCTRS.
Pucher, J., Dill, J., \& Handy, S. (2010). Infrastructure, programs, and policies to increase bicycling: an international review. Preventive Medicine, 50, S106-S125.

Raia Junior, A. A. (2000). Acessibilidade e mobilidade na estimativa de um índice de potencial de viagens utilizando redes neurais artificais e sistemas de informações geográficas (Tese de Doutorado). Universidade de São Paulo, São Carlos, Brasil.

Rodrigues da Silva, A. N., Raia Junior, A. A. \& Bocanegra, C. W. R. (2002). Exploring an ANN modeling approach that combines accessibility and mobility into a single trip potential index for strategic planning. In TRB 81st Annual Meeting Compendium of Papers. Washington, DC, EUA: TRB.

Ryley, T. (2006). Estimating cycling demand for the journey to work or study in West Edinburgh, Scotland. Transportation Research Record: Journal of the Transportation Research Board, 1982, 187-193.

Vá de Bike. (2015). Ciclovia mais que dobrou o número de bicicletas na Avenida Paulista. Recuperado em 02 de novembro de 2016, de http://vadebike.org/2015/09/ contagem-ciclistas-paulista-aumento-fluxo-ciclovia

Wardman, M., Tight, M., \& Page, M. (2007). Factors influencing the propensity to cycle to work. Transportation Research Part A: Policy and Practice, 41(4), 339-350. 


\section{Errata}

No artigo "Estudo exploratório da demanda potencial para um sistema de compartilhamento de bicicletas pedelecs" com número de DOI: 10.1590/2175-3369.009.SUPL1.A009, publicado no periódico Urbe - Revista Brasileira de Gestão Urbana, 9(SUPL1): 372-384, nas páginas 374, 376, 378, 380, 382, 384:

Onde se lia:

Silva, A. R. N.

Leia-se:

Rodrigues da Silva, A. N. 